\title{
Multiple Uterine Fibroids in a Young Unmarried Woman
}

\author{
Mounika Pottala ${ }^{1}$, Shubhada Suhas Jajoo ${ }^{2}$ \\ ${ }^{1}$ Department of Obstetrics and Gynaecology, Datta Meghe Institute of Medical Sciences, Wardha, Maharashtra, India. \\ ${ }^{2}$ Department of Obstetrics and Gynaecology, Datta Meghe Institute of Medical Sciences, Wardha, Maharashtra, India.
}

\section{INTRODUCTION}

Uterine fibroids are a unique issue in gynaecology and reproductive medicine. The incidence is $20 \%$ in women in the age group of 30 yrs. Nulliparity increases the risk. The most common presentations are menstrual irregularity and pressure symptoms. Gynaecologists should counsel about the complications and fertility problems recurrence of fibroids after treatment like UAE (Uterine Artery Embolisation) and contraceptive procedures and importance of frequent hospital check-up visits. There are several non-invasive methods to treat fibroids available now a days. In case recurrence of fibroids or multiple fibroids, the final options are myomectomy to (conserve the uterus for reproduction) or hysterectomy. In this case report, we highlight the management for multiple recurrent fibroids in an unmarried nulliparous woman who wanted to conserve her fertility. She was managed by myomectomy.

Fibroid is the most common benign tumour of uterus and in females also the most common benign tumour. Histologically, it is composed of smooth muscle and fibrous connective tissue, so named leiomyoma. These are oestrogen dependent tumours, most commonly seen in reproductive age group. Hysterectomy is the effective treatment in women who are satisfied with their family completion. But many uterus sparing options are available and should be discussed with the patients. Myomectomy is the suitable approach in unmarried nulliparous women who wants to conserve their fertility. Factors causing fibroid not yet completely understood. There are so many factors responsible for fibroids like lifestyle, diet, work stress, consumption of caffeine, reproductive factors, hormonal factors, alcohol and smoking, fattiness, microorganism infections and lastly environmental factors.

\section{PRESENTATION OF CASE}

A 22-year-old female patient presented to the gynaecological OPD in AVBRH with complaints of progressive distension of abdomen since 6 months along with discomfort in abdomen. There were no complaints of nausea, vomiting, irregular bowel and bladder habits, decreased appetite, and weight reduction. Her age of menarche was 14 yrs. with regular periods. Menarche occurred at 14 years of age, and her menstrual periods had always been regular. There was no recent sexual activity and was not currently taking oral contraceptives.

According to the patient's history, she had h/o fibroids 5 yrs. back for which she had undergone UAE (Uterine Artery Embolisation) which conservative management, with a gap of 2 years. No significant family history. On Physical examination there was a firm, irregular, non-tender mobile mass arising from the pelvis, corresponding in size to a pregnant uterus of 22 weeks' gestation. Pregnancy was excluded. Blood $\mathrm{Hb}$ was $12.6 \mathrm{~g} / \mathrm{dL}$. The remaining laboratory results were within physiological limits.
Corresponding Author: Dr. Shubhada Suhas Jajoo, Department of Obstetrics and Gynaecology, Datta Meghe Institute of Medical Sciences, Wardha, Maharashtra, India.

E-mail: mounika.pottala14@gmail.com

DOI: $10.14260 / \mathrm{jemds} / 2020 / 239$

Financial or Other Competing Interests: None.

How to Cite This Article:

Pottala M, Jajoo SS. Multiple uterine fibroids in a young unmarried woman. J. Evolution Med. Dent. Sci. 2020;9(13):11101112, DOI: $10.14260 /$ jemds/2020/239

Submission 08-01-2020,

Peer Review 06-03-2020,

Acceptance 12-03-2020,

Published 30-03-2020.

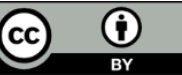


An $18 \times 14 \mathrm{cms}$ globular mass in the uterus was found during trans abdominal sonography. There were multiple small fibroids along with it. Because of the bulkiness of the uterus, bilateral adnexa along with the ovaries could not be appreciated. There was no ascites and no evidence of hydronephrosis. The patient was counselled and explained about uterine fibroid and its complications. Informed and written consent was taken for surgery (for both myomectomy and hysterectomy).

\section{Intraoperative Findings}

- The uterus was grossly enlarged by a large fibroid measuring $16 \mathrm{~cm} \times 10 \mathrm{~cm}$.

- Both ovaries and fallopian tubes were normal.

- Bulky uterus with 31 small fibroids identified.
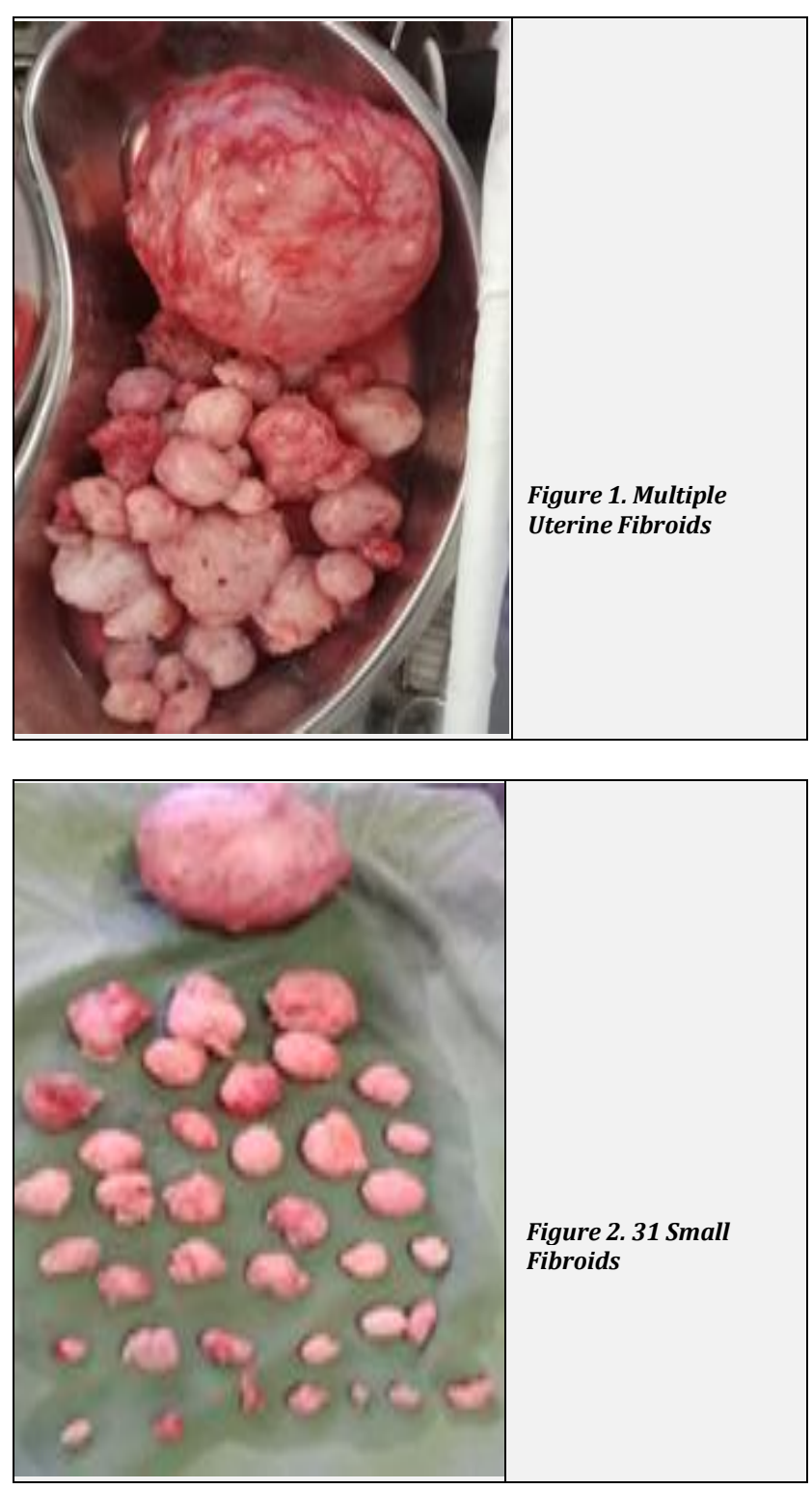

The uterus was taken out of the abdominal cavity and through a fundal incision myomectomy of the large tumour was achieved. The excision site closed with continuous catgut sutures. On Cut section the gross specimen showed small white coloured nodules with a whorled appearance with fibro elastic consistency which is a suggestive feature of leiomyoma. The specimen was sent for histopathology. Which confirmed the diagnosis of a benign fibroid of the uterus.
The postoperative course of the patient was uneventful, on day 7 postoperative she was discharged. Advised for sixmonth follow-up with repeat ultrasonography. We have counselled regarding recurrence and future fertility. Though she was an adolescent and sexually active, she was counselled for family planning and to allow wound healing and full recovery we have advised not to conceive for at least one year to.

\section{DISCUSSION}

Aetiology of leiomyomas is still unknown, but in response to both oestrogen and progesterone stimulation leiomyomas are known to grow, and their prevalence increases throughout the reproductive years and after menopause there will be reduction in size.[1-4] In fibroids compared to normal myometrial tissue there is high presence of hormonal receptors like oestrogen progesterone and aromatase.[5-7] fibroid growth is influenced by certain conditions like early menarche, obesity, exogenous oestrogen exposure, obesity, hormonal imbalance and pregnancy.[8-10]In my patient pregnancy and obesity and also exogenous hormonal supplementations are excluded. A bit of genetic component of the pathogenesis of uterine leiomyomas has also been proposed.[11,12 ] chromosomes 6, 7, 12, and 14 showing high frequency metabolic mutations have been reported in fibroids.[11,12] It is still a question how these mutations eventually leads to the formation of a leiomyomas. According to few theorists that intrinsic myometrial anomalies and endometrial injury play important roles. This is a possible explanation of formation of leiomyoma among menstruating adolescents, but why some lesions appear sooner rather than later in adult life is still an unsolved question.[13,14] It is due to soon after menarche there is possibility of sex steroid stimulation [15,16].Irregular uterine bleeding, pelvic pain, and pressure symptoms, such as urinary frequency or urgency are the symptomatic presentation of uterine fibroids in adolescents.[14] My patient presented with a pelvic mass with abnormal uterine bleeding with urinary frequency.

In evaluating a woman with a pelvic mass Pelvic examination is the initial step. Ultrasonography should be the initial diagnostic approach in suspicion of fibroid.[17] MRI (magnetic resonance imaging) is the gold standard for the evaluation of pelvic soft tissue tumours is however in low source settings it is poorly available.[17] Generally Computed tomography (CT) scanning is not recommended for the evaluation of uterine fibroids. ${ }^{[18,19]}$ Depends on the patient's age and family planning goals, as well as tumour size and symptomatology the treatment varies for fibroids. Asymptomatic fibroids can be kept under observation. The possibility of malignant transformation of fibroids can be eliminated by regular evaluation and fallow up.[20.21] For symptomatic fibroids in adolescents there are no treatment guidelines. Surgical treatments such as myomectomy, myolysis, and hysterectomy can be performed when appropriate. For young women with symptomatic fibroids Myomectomy is a common procedure It does not interfere with the hormonal balance of the adolescent, it preserves fertility, and the recurrence rate is also low.[14] There are several surgical options like laparoscopy, laparotomy, hysteroscopy Depending on the number, size, and location of 
the fibroids. Myomectomy can be performed in adolescents who wants to preserve their fertility. Hysterectomy is often performed for women with symptomatic fibroids who do not desire to retain fertility.

To allow a more rapid recovery In some cases Medical treatments and some invasive procedures can be performed.[22] However, there is no supportive evidence the use of such treatments in adolescents.[14] Uterine artery embolization (UAE) is one of the option. The explanation behind the UAE is it embolizes the ascending branches of uterine artery causes necrosis and shrinkage of the tumour by blocking the perfusion of fibroid. Complete loss of fibroid perfusion by embolize. [23] For adults who wants to retain their fertility the UAE has got limited applicability because of impaired blood flow which will damage the ovarian and fallopian tubes:[24] Because of risks with long term treatment Medical management is only used for short-term duration. Proposed drugs for medical management are Gonadotropinreleasing hormone (GnRH) agonists, selective oestrogen receptor modulators (SERMs), antiprogestin (RU486), and aromatase inhibitors. ${ }^{[25]}$ There is limited evidence in managing uterine leiomyomas by medical management. Ulipristal acetate (like sPRMs) and GNRHA gonadotropin releasing hormone agonists like drugs are other conservative modalities in gynaecology. It is somewhat difficult to preserve fertility in adolescents with symptomatic fibroids. Myomectomy is the best procedure in the adolescent group, in view of preserving fertility $26,27,28,29$.

\section{REFERENCES}

[1] Grapsa D, Smymiotis V, Hasiakos D, et al. A giant uterine leiomyoma simulating an ovarian mass in a 16 -year-old girl: a case report and review of the literature. Eur J Gynaecol Oncol 2006;27(3):294-6.

[2] Bekker G, Gavrilescu T, Rickets-Holcomb L, et al. Symptomatic fibroid uterus in a 15-year-old girl. Int Surg 2004;89(2):80-2.

[3] Diesen DL, Price TM, Skinner MA. Uterine leiomyoma in a 14-year-old girl. Eur J Pediatr Surg 2008;18(1):53-5.

[4] Fields KR, Neinstein LS. Uterine myomas in adolescents: case reports and a review of the literature. J Pediatr Adolesc Gynecol 1996;9(4):195-8.

[5] Rein MS, Barbieri RL, Friedman AJ. Progesterone: a critical role in the pathogenesis of uterine myomas. Am J Obstet Gynecol 1995;172(1 Pt 1):14-8.

[6] Brandon DD, Erickson TE, Keenan EJ, et al. Estrogen receptor gene expression in human uterine leiomyomas. J Clin Endocrinol Metab 1995;80(6):1876-81.

[7] Sumitani H, Shozu M, Segawa T, et al. In situ estrogen synthesized by aromatase P450 in uterine leiomyoma cells promotes cell growth probably via an autocrine/intracrine mechanism. Endocrinology 2000;141(10):3852-61.

[8] Laughlin SK, Baird DD, Savitz DA, et al. Prevalence of uterine leiomyomas in the first trimester of pregnancy: an ultrasound-screening study. Obstet Gynecol 2009;113(3):630-5.

[9] Chen CR, Buck GM, Courey NG, et al. Risk factors for uterine fibroids among women undergoing tubal sterilization. Am J Epidemiol 2001;153(1):20-6.
[10] Borgfeldt C, Andolf E. Transvaginal ultrasonographic findings in the uterus and the endometrium: low prevalence of leiomyoma in a random sample of women age 25-40 years. Acta Obstet Gynecol Scand 2000;79(3):202-7.

[11] Ligon AH, Morton CC. Leiomyomata: heritability and cytogenetic studies. Hum Reprod Update 2001;7(1):8-14.

[12] Ligon AH, Morton CC. Genetics of uterine leiomyomata. Genes Chromosomes Cancer 2000;28(3):235-45.

[13] Parker WH. Etiology, symptomatology and diagnosis of uterine myomas. Fertil Steril 2007;87(4):725-36.

[14] Moroni RM, Vieira CS, Ferriani RA, et al. Presentation and treatment of uterine leiomyoma in adolescence: a systematic review. BMC Womens Health 2015;15:4.

[15] Baird DD, Dunson DB, Hill MC, et al. High cumulative incidence of uterine leiomyoma in black and white women: ultrasound evidence. Am J Obstet Gynecol 2003;188(1):100-7.

[16] Marshall LM, Spiegelman D, Barbieri RL, et al. Variation in the incidence of uterine leiomyoma among premenopausal women by age and race. Obstet Gynecol 1997;90(6):967-73.

[17] Karasick S, Lev-Toaff AS, Toaff ME. Imaging of uterine leiomyomas. AJR Am J Roentgenol 1992;158(4):799-805.

[18] De Rooy CG, Wiegerinck MA. A 15-year-old girl with an expansively growing tumour. Eur J Obstet Gynecol Reprod Biol 1986;22(5-6):373-7.

[19] Casillas J, Joseph RC, Guerra JJ Jr. CT appearance of uterine leiomyomas. Radiographics 1990;10(6):999-1007.

[20] Lumsden MA. Modern management of fibroids. Obstet Gynaecol Reprod Med 2013;23(3):65-70.

[21] Falcone T, Walters MD. Hysterectomy for benign disease. Obstet Gynecol 2008;111(3):753-67.

[22] Seracchioli R, Rossi S, Govoni F, et al. Fertility and obstetric outcome after laparoscopic myomectomy of large myomata: a randomized comparison with abdominal myomectomy. Hum Reprod 2000;15(12):2663-8.

[23] Volkers NA, Hehenkamp WJ, Birnie E, et al. Uterine artery embolization in the treatment of symptomatic uterine fibroid tumours (EMMY trial): periprocedural results and complications. J Vasc Interv Radiol 2006;17(3):471-80.

[24] Goldberg J, Pereira L, Berghella V. Pregnancy after uterine artery embolization. Obstet Gynecol 2002;100(5 Pt 1):869-72.

[25] Lethaby AE, Vollenhoven BJ. An evidence-based approach to hormonal therapies for premenopausal women with fibroids. Best Pract Res Clin Obstet Gynaecol 2008;22(2):307-31.

[26] Perkins JD, Hines RS, Prior DS. Uterine leiomyoma in an adolescent female. J Natl Med Assoc 2009;101(6):611-3.

[27] Michala L, Vlachos GD, Belitsos P, et al. Uterine fibroid in an adolescent: an unlikely diagnosis? J Obstet Gynaecol 2010;30(2):207-8.

[28] Berveiller P, Mir O, Menu Y, et al. Fertility-sparing approach in a teenager with uterine tumour diagnosed as a sarcoma on imaging. Gynecol Obstet Invest 2010;69(3):157-9.

[29] Tsili AC, Lentoudi ED, Argyropoulou MI, et al. Fibromatous uterus in a 16-year-old girl: a case report. Case Rep Med 2010;2010:932762. 